\title{
Effect of low sodium intake and $\beta$-blockade on renin synthesis and secretion in mice with unilateral ureteral ligation
}

\author{
Yanling Zhang, Junyan Wu, Zhaoqiang Zhang, Bingxiang Wang, Peng Chen and Xuean Jing
}

\begin{abstract}
We previously reported that sodium depletion increased renin secretion from the normal kidney in mice. We postulated that the combined procedures of sodium depletion and $\beta$-adrenoceptor blockade would affect the activity of the renin-angiotensin system. To test this hypothesis, we investigated the interaction of low sodium intake (LSI) and propranolol (PRO) on renin synthesis and secretion. To prevent the influence of tubule flow on renin secretion, mice with a left hydronephrotic kidney were used. LSI increased plasma renin concentration (PRC) 5.6 -fold in the right renal vein $(P<0.01)$. There was no net increase of PRC in the left renal vein. Tissue renin concentration (TRC) was elevated 3.6-fold and 1.3 -fold in the right and left kidneys $(P<0.01)$, respectively. After administration of PRO, PRC decreased by $34 \%$ in the right renal vein and $47 \%$ in the aorta $(P<0.05)$; TRC was reduced by $37.5 \%$ in the right and $29.3 \%$ in the hydronephrotic kidneys $(P<0.05)$. The combination of LSI and PRO increased PRC 3.4-fold and 1.8-fold in the right $(P<0.01)$ and left renal veins $(P<0.05)$, respectively. TRC increased 3.4-fold in the right $(P<0.01)$ but only $61 \%$ in the left kidneys $(P<0.05)$. The pattern in change of renin $\mathrm{mRNA}$ levels was similar to TRC but the absolute amount was smaller. There were correlations between PRC and renin mRNA, and between TRC and renin mRNA in both kidneys $(P<0.001)$. Thus, LSI increased renin synthesis in both kidneys. However, there was no apparent renin secretion in the hydronephrotic kidney. PRO treatment suppressed renin synthesis and renin secretion, irrespective of hydronephrosis and LSI. The macula densa is critical for renin secretion under all of the circumstances studied. Hypertension Research (2010) 33, 1258-1263; doi:10.1038/hr.2010.167; published online 30 September 2010
\end{abstract}

Keywords: $\beta$-blockade; hydronephrosis; macula densa; renin synthesis; sodium depletion

\section{INTRODUCTION}

It is generally accepted that the circulating renin-angiotensin-aldosterone system is involved in the control of total body sodium. However, changes in sodium balance cause major alterations in renin secretion. This may be a direct effect of sodium delivery to the macula densa cells, or an indirect action mediated by neural or humoral signals induced by the alteration in extracellular sodium concentration or fluid volume. ${ }^{1-3}$

Of the hypotheses proposed for the regulation of renin secretion by sodium, the macula densa theory has received most attention. ${ }^{4-6}$ In the murine macula densa cell line MMDD1, an increase in intracellular sodium chloride reduces the effect of salt restriction on tubuloglomerular feedback and renin secretion. ${ }^{6}$ In normal subjects during slow sodium loading, a volume receptor elicited reduction in renal nervous activity via $\beta_{1}$-adrenoceptors decreases renal tubular sodium reabsorption proximal to the macula densa, leading to increased $\mathrm{NaCl}$ concentration at the macula densa and subsequent inhibition of renin secretion. ${ }^{7}$ A low sodium diet stimulates renin secretion from the kidney in dogs. ${ }^{8}$ However, the role of the macula densa in the regulation of renal renin synthesis and secretion remains unclear. ${ }^{89}$ The response in renin secretion is known to be the result of multiple interactions. ${ }^{10}$

Studies have demonstrated that $\beta$-adrenergic agonists increase renin release. ${ }^{1-14}$ A moderate increase in the renal sympathetic nerve activity produced by graded common carotid occlusion also stimulates renin secretion. This increase was prevented by $\beta$-adrenoceptor blockade or surgical denervation of the kidney. ${ }^{15,16}$ In mice, the release of renin from dense-core vesicles of juxtaglomerular granular cells in the kidney was modulated by normal rates of catecholamine release from the sympathetic nerve terminals. ${ }^{17}$ In renally denervated rats, an enhanced sensitivity of the $\alpha 1$-adrenoceptors to adrenergic agonists and an increase of AT1 receptor functionality in the renal vasculature were observed, suggesting an interaction between the sympathetic nervous system and the renin-angiotensin system in terms of a crosstalk relationship. ${ }^{18}$ An increase in the renal sympathetic nervous activity was correlated with an increase in the renal 
renin-angiotensin system content in low-salt-treated rats. ${ }^{19}$ However, the exact mechanism of the regulation of renin secretion and synthesis by sodium and adrenoceptors is not fully understood. The aim of this study was to examine the interaction of $\beta$-adrenoceptor blockade and low sodium intake (LSI) on renin synthesis, and secretion in mice with a hydronephrotic kidney.

\section{METHODS}

\section{Animals and experimental protocol}

In all, 40 male Balb/C mice, aged 10 weeks, were used in this study. The experiments were conducted according to the guidelines of the National Research Council and were approved by the local ethics committee. All mice weighing $25-30 \mathrm{~g}$ were subjected to left ureteral ligation. They were anesthetized by intraperitoneal injection of $60 \mathrm{mg} \mathrm{kg}^{-1}$ sodium pentobarbitone. The left kidney was exposed by a flank incision and the ureter was doubly ligated with 1.0 silk suture. Antibiotic powder (cicatrin, containing zinc bacitracin and neomycin sulfate) was dusted in the abdominal cavity, and the incision was closed. Surgery time was $10-15$ min per animal. The mice were maintained on a standard laboratory diet and had free access to tap water. At 4 weeks after the operation, the left kidney was hydronephrotic. ${ }^{20,21}$ At this time the following studies were performed. The control group $(n=10)$ were fed regular mouse diet. The LSI $(n=10)$ group were fed a low sodium diet $(0.1 \% \mathrm{NaCl})$ and injected with frusemide $(2 \mathrm{mg}$ ) on day 1 . The propranolol (PRO, $n=10)$ group were given PRO $12 \mathrm{mg} \mathrm{kg}^{-1}$ per day in drinking water. The combined procedure group (LSI+PRO, $n=10$ ) were treated with LSI and PRO. The experimental procedure was carried out in the four groups for 2 weeks.

At 2 weeks after the experimental intervention started, the mice were anesthetized and both the kidneys were exposed through a midline incision. Briefly, a blood sample $(20 \mu \mathrm{l})$ was taken from the left and right renal veins and from the abdominal aorta. ${ }^{20-22}$ Plasma was separated from each blood sample by microcentrifuge. After blood sampling, the mouse was immediately killed. The right and left kidneys were removed and divided into two along their longitudinal plane. One half was used to determine the renal renin concentration and the other for renin mRNA.

\section{Measurement of blood pressure (BP)}

Mean arterial pressure was recorded every 2 days before and throughout the experiment in conscious mice, by the tail cuff method as described previously. ${ }^{22}$

\section{Measurement of plasma renin concentration (PRC) and tissue renin concentration (TRC)}

PRC was measured in the blood from the aorta and renal veins using a radioimmunoassay described previously. ${ }^{20-22}$ The renin value was expressed in Goldblatt units ( $1 \mathrm{GU}=0.42 \mu \mathrm{g}$ of angiotensin I formation) per milliliter of plasma. The $1 / 2$ kidneys removed from each mouse were weighed and homogenized in $1 \mathrm{ml}$ buffer. Aliquots $(20 \mu \mathrm{l})$ were used for renin measurement. Renin concentration was expressed in GU per gram of kidney weight and GU per kidney.

\section{Measurement of renin mRNA in the kidney}

Total RNA in the kidney was isolated using Trizol reagent (Invitrogen, Grand Island, NY, USA) according to the manufacturer's instructions. The amount of RNA isolated was measured by absorbance at $260 \mathrm{~nm}$. An aliquot of each sample of RNA was diluted in $20 \times$ standard saline citrate $\left(3 \mathrm{moll}^{-1} \mathrm{NaCl}\right.$, $0.3 \mathrm{moll}^{-1}$ sodium citrate) and denatured in formaldehyde. The dot-blot hybridization for measuring renin mRNA in the total RNA sample was carried out as described previously. ${ }^{20-22}$ To analyze the value of renin mRNA between kidneys, the results from the renin signal were expressed relative to a value of $100 \mathrm{U}$ in the control kidney. The mRNA was then referred back to the tissue weight of the sample, as described previously. ${ }^{20-22}$

\section{Statistical analysis}

Statistical analysis was performed using SPSS 13.0 (SPSS Inc., Chicago, IL, USA). Data are presented as the mean \pm s.e.m. Unpaired $t$-test was used to compare two values between different groups of animals. Multiple groups were analyzed with analysis of variance followed by post-hoc test. The linear regression between PRC, TRC and renin mRNA levels was analyzed with PEMS 3.1 for Windows. $P<0.05$ was considered significant.

\section{RESULTS}

All mice were in good condition, and at the end of the experiments there were no differences in body weights between animals. BP did not differ among the groups after unilateral ureteral ligation. In the 2 weeks of LSI, BP did not change. However, PRO treatment lowered $\mathrm{BP}$ in mice (Figure 1). In animals treated with LSI and PRO together, BP did not significantly change, indicating that there might be a complex response between these two procedures on $\mathrm{BP}$ in the hydronephrotic mouse model.

\section{Changes in kidney weights}

In mice with left ureteral ligation, all left kidneys were hydronephrotic. During postmortem, liquid in the left kidneys was removed and the kidneys were weighed. In control mice the right kidney weighed $0.26 \pm 0.05 \mathrm{~g}$ and left hydronephrotic kidney $0.12 \pm 0.02 \mathrm{~g}(P<0.01)$. In LSI mice, the right kidney weights were $0.21 \pm 0.02 \mathrm{~g}$ and the left kidney weights were significantly lower at $0.10 \pm 0.01 \mathrm{~g},(P<0.01)$. In both PRO and PRO+LSI groups, the left hydronephrotic kidney weights were also lower than the contralateral kidney. Light microscopy confirmed that the tissue in the left hydronephrotic kidney was much thinner than that in the contralateral kidney, resulting in the reduction of the left kidney weight.

\section{PRC in the aorta and renal veins}

PRC in blood from the aorta and from both the right and left renal veins was measured with radioimmunoassay. In control animals PRC was $26.7 \pm 2.6 \mathrm{mGU} \mathrm{ml}^{-1}$ in the aorta, $37.2 \pm 3.0 \mathrm{mGU} \mathrm{ml}^{-1}$ in the right renal vein and $27.7 \pm 2.4 \mathrm{mGUml}^{-1}$ in the left renal vein draining the hydronephrotic kidney. The value in the left renal vein was lower than in the right renal vein $(P<0.05$, Figure 2$)$. In LSI mice treated with low sodium diet and frusemide injection, PRC rose to $166.8 \pm 30.4 \mathrm{mGU} \mathrm{ml}^{-1}$ in the aorta $(P<0.01)$ and $247.1 \pm 32.8 \mathrm{mGU} \mathrm{ml}^{-1}$ in the right vein, an increase of 5.6-fold,

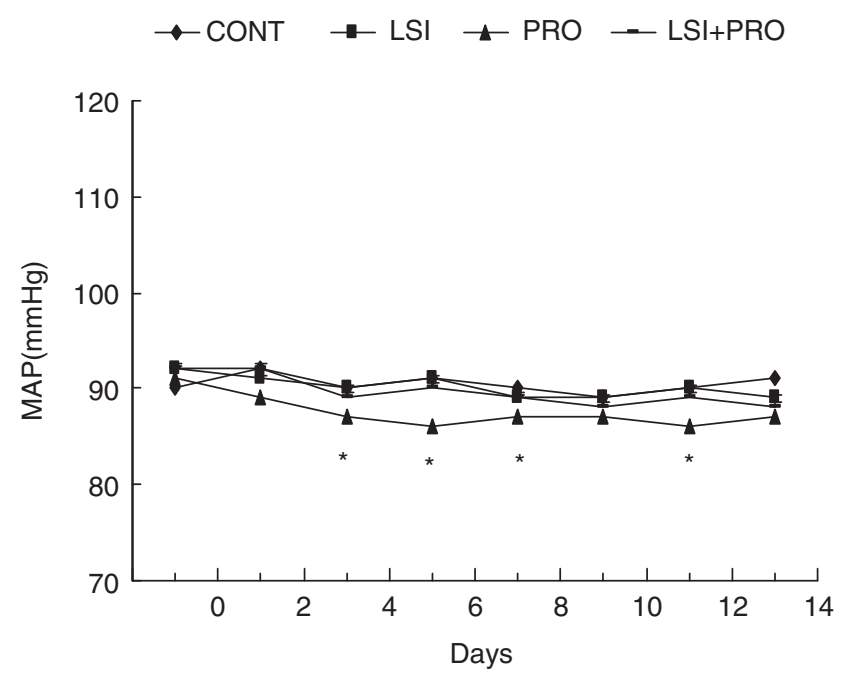

Figure 1 Effects of low sodium intake (LSI), propranolol (PRO) and $\mathrm{LSI}+\mathrm{PRO}$ on mean arterial pressure (MAP) in mice ( $n=10$ each group). Data are mean \pm s.e.m. ${ }^{*} P<0.05$. CONT, control. 


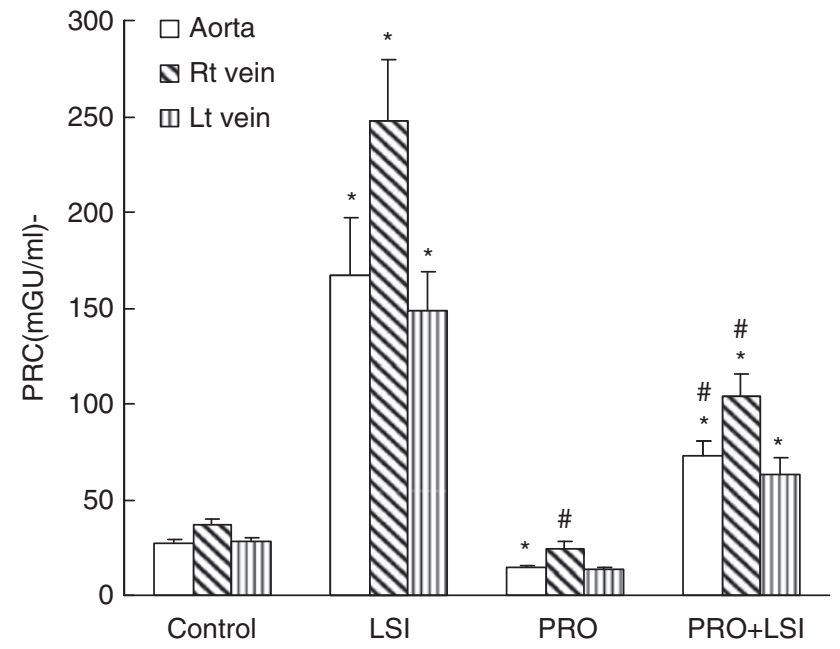

Figure 2 Plasma renin concentration (PRC) in the aorta, right (Rt) and left (Lt) renal veins in four groups of mice ( $n=10$ each group, the left ureteral ligation was performed in all mice) after treatment with low sodium intake (LSI), propranolol (PRO) and LSI+PRO. Data are expressed as mean \pm s.e.m. ${ }^{*} P<0.05$ vs. control; ${ }^{*} P<0.05$ vs. LSI group. GU, Goldblatt unit.

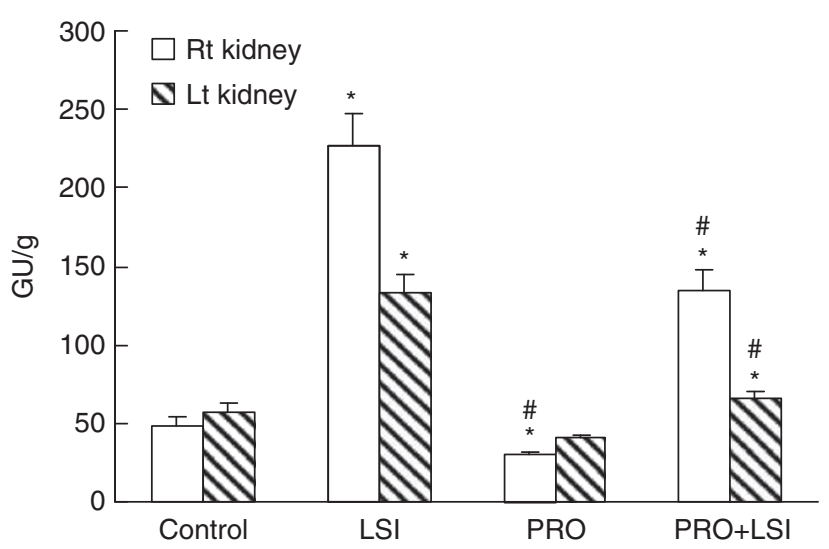

Figure 3 Tissue renin concentration in the right (Rt) and left (Lt) hydronephrotic kidneys in mice treated with low sodium intake (LSI), propranolol (PRO) and LSI+PRO. $n=10$ each group. Values are mean \pm s.e.m. ${ }^{*} P<0.05$ vs. control; ${ }^{\#} P<0.05$ vs. LSI group.

which was higher than the value in the aorta $(P<0.01)$. The value in the left renal vein did not differ from that in the aorta. In PRO mice treated with PRO, PRC was decreased to $14.1 \pm 1.3 \mathrm{mGU} \mathrm{ml}^{-1}$ in the aorta, $24.5 \pm 3.4 \mathrm{mGU} \mathrm{ml}^{-1}$ in the right renal vein and $13.9 \pm 1.1 \mathrm{mGU} \mathrm{ml}^{-1}$ in the left renal vein. In LSI+PRO mice, PRC was $72.4 \pm 7.7,103.9 \pm 11.6$ and $63.1 \pm 8.7 \mathrm{mGU} \mathrm{ml}^{-1}$ in the aorta, right and left renal veins, respectively, an increase of 1.3- to 1.8-fold $(P<0.01)$ compared with the value in control group. However, all values in LSI+PRO mice were less than in mice treated with LSI alone $(P<0.01$, Figure 2$)$. The data showed there was no net increase of PRC in the hydronephrotic kidneys. LSI increased PRC levels from the right kidneys, whereas PRO treatment reduced PRC levels from the right organs. Thus PRO can attenuate renin secretion stimulated by LSI.

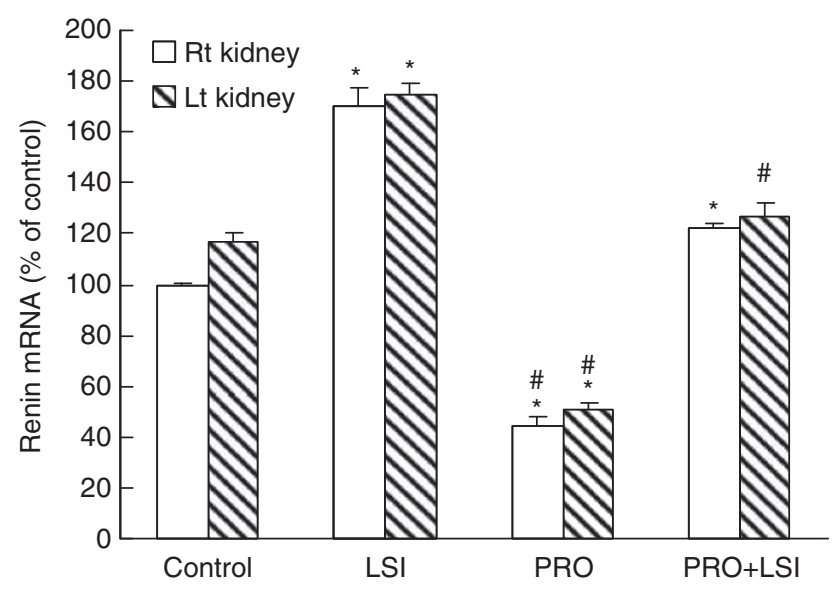

Figure 4 Renin mRNA levels in the right (Rt) and left (Lt) hydronephrotic kidneys. Renin mRNA expressed as a percentage of the value in the normal kidney in control mice. Animals were treated with the following procedures: control, low sodium intake (LSI), propranolol (PRO) and LSI+PRO. $n=10$ each group. Values are mean \pm s.e.m. ${ }^{*} P<0.05$ vs. control; ${ }^{\#} P<0.05$ vs. LSI group.

\section{TRC in both kidneys}

TRC was measured in both kidneys with radioimmunoassay. TRC was $48.8 \pm 5.2 \mathrm{GUg}^{-1}$ in the right and $57.4 \pm 4.9 \mathrm{GUg}^{-1}$ in the left hydronephrotic kidneys in the control mice (Figure 3). In LSI mice, TRC was increased to $227.3 \pm 19.8 \mathrm{GUg}^{-1}$ in the right kidney and to $133.9 \pm 11.3 \mathrm{GU} \mathrm{g}^{-1}$ in the left $(P<0.001)$. In PRO mice, TRC was decreased to $30.5 \pm 1.4 \mathrm{GUg}^{-1}$ in the right kidney and $40.6 \pm 2.1 \mathrm{GU} \mathrm{g}^{-1}$ in the left. There was a significant change in values in both kidneys compared with the control $(P<0.05)$. In LSI+PRO mice, TRC was $134.1 \pm 13.9 \mathrm{GUg}^{-1}$ in the right kidney and $65.4 \pm 4.8 \mathrm{GU} \mathrm{g}^{-1}$ in the left hydronephrotic kidneys, an increase of 3.4 -fold and $61 \%$, respectively, compared with the PRO alone group $(P<0.01)$. There was also a significant difference in TRC in both kidneys between LSI+PRO and LSI alone $(P<0.01)$. PRO had a depressive effect on renin levels during sodium depletion and in the presence or absence of hydronephrosis. The results showed that there was an interaction between sodium depletion and PRO on renin production in the kidneys. When the values were expressed per kidney (data not shown) the response was similar to that expressed per gram of kidney weight.

\section{Renin mRNA levels in both kidneys}

The change in renin mRNA levels in the kidney was assessed by dotblot quantification. The results from four groups are shown in Figure 4. In control mice, renin mRNA was $100 \mathrm{Ug}^{-1}$ in the right kidney and $116.4 \pm 3.9 \mathrm{Ug}^{-1}$ in the hydronephrotic kidney $(P<0.05)$. In LSI group, the value of renin mRNA was $169.8 \pm 7.9 \mathrm{Ug}^{-1}$ $(P<0.01)$ in the right normal kidney and $175.0 \pm 4.1 \mathrm{Ug}^{-1}$ $(P<0.001)$ in the hydronephrotic kidney. In PRO group, renin mRNA level decreased from the control level to $44.1 \pm 3.7 \mathrm{Ug}^{-1}$ $(P<0.001)$ in the right kidney and to $50.6 \pm 3.0 \mathrm{Ug}^{-1}$ in the hydronephrotic kidney $(P<0.001)$. In LSI+PRO mice, renin mRNA level was $122.3 \pm 2.1 \mathrm{Ug}^{-1}(P<0.05)$ in the right and $127.0 \pm 5.1 \mathrm{Ug}^{-1}$ $(P<0.01)$ in the left hydronephrotic kidneys, a decrease of $27 \%$ of the levels in both kidneys compared to mice in the LSI group.

Linear regression analysis showed that there was positive correlation between PRC and renin mRNA level in the right kidney $\left(r^{2}=0.5723\right.$, 

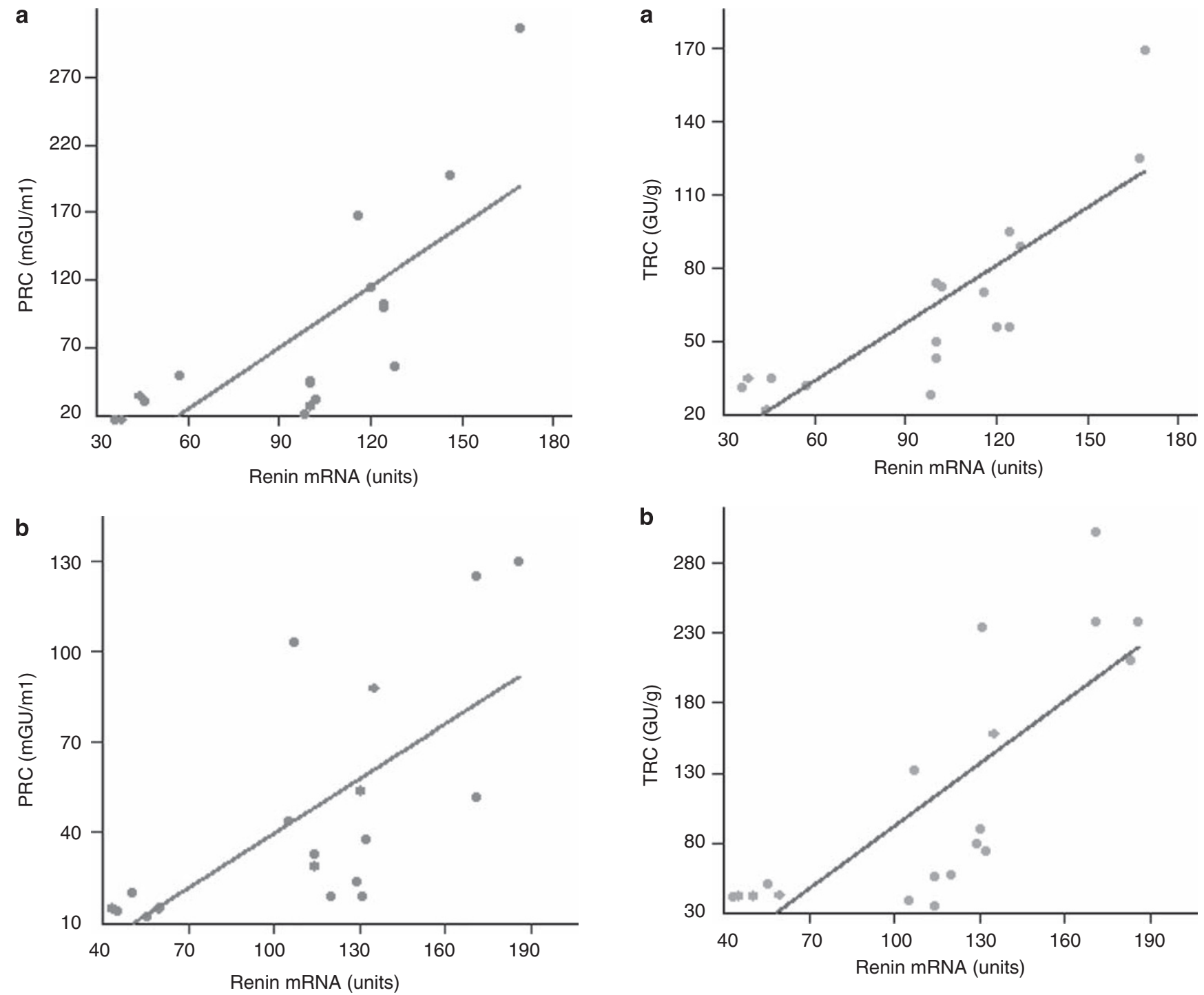

Figure 5 Correlation between plasma renin concentration (PRC) and renin mRNA levels induced by the different procedures in the right (a, $\left.r^{2}=0.5723, P<0.001\right)$ and left hydronephrotic kidneys (b, $r^{2}=0.4746$, $P<0.01) . n=40$. GU, Goldblatt unit.

$P<0.001$, Figure 5a) and in the left hydronephrotic kidney $\left(r^{2}=0.4746, P<0.01\right.$, Figure $\left.5 b\right)$. Meanwhile, a positive correlation was seen between TRC and renin mRNA in the right kidney $\left(r^{2}=0.7117, P<0.001\right.$, Figure 6a) and in the left hydronephrotic kidney $\left(r^{2}=0.6146, P<0.001\right.$, Figure $\left.6 \mathrm{~b}\right)$. These results show that the change of renin gene expression in the kidney is paralleled with PRC and TRC in mice treated with LSI and PRO. Again, there was a significant interaction between LSI and PRO on renin synthesis and secretion.

\section{DISCUSSION}

In the previous study, when the left ureter of mice was ligated the kidney became hydronephrotic and lost all of its tubular structure, so that it primarily consists of an arteriole system and glomeruli. ${ }^{21}$ In this study, an assessment of the secretion level was carried out by measuring the concentration of renin in the right, left renal veins and aorta. It

Figure 6 Correlation between tissue renin concentration (TRC) and renin mRNA levels caused by the different treatments in the right $\left(\mathrm{a}, r^{2}=0.7117\right.$, $P<0.001$ ) and left hydronephrotic kidneys (b, $r^{2}=0.6146, P<0.001$ ). $n=40$. GU, Goldblatt unit.

does enable us to say whether there was either net secretion or net removal of renin as the blood traverses the kidney structure. In the control state, there was no net secretion of renin in the hydronephrotic kidney. Even the powerful procedure of LSI and furosemide administration was unable to provide a net increase of PRC in the left renal vein, suggesting that the hydronephrotic kidney apparently ceased to secrete renin. Thus the macula densa has a pivotal role for renin to be released following chronic stimulation. However, a LSI caused a rise in TRC and renin mRNA levels in both the normal and the hydronephrotic kidneys, suggesting that the macula densa may be not critical for renin synthesis stimulated by sodium depletion.

There have been a number of studies on the effect of sodium on renin release but the mechanism by which sodium alters renin secretion is unclear. $^{23-28}$ Renin secretion can be influenced by the flow and/or composition of fluid at the macula densa. ${ }^{29-31}$ In some studies, the tubule was perfused with different concentrations of sodium chloride 
and the renin release measured. ${ }^{32,33}$ When a solution of high sodium chloride composition was given, renin release was lowered. These studies support the concept that renin secretion is regulated by the macula densa. However, it has been reported that the renin secretion, stimulated by the diuretic ethacrynic acid, is independent of the presence of $\mathrm{Na}^{+}, \mathrm{Cl}^{-}$and $\mathrm{Ca}^{++} .{ }^{34}$ There can be little doubt that the macula densa is important in the regulation of renin release, but the role of the macula densa in the control of renin synthesis remains unclear. This study showed that sodium depletion increased renin synthesis in the hydronephrotic kidney in which there was no macula densa.

Activation of renal $\beta$-adrenoceptors stimulates renin release and mediates increased renin secretion rate when renal nerves are electrically stimulated. ${ }^{27,35-38}$ The administration of $\beta$-adrenergic antagonists could block the increase in renin secretion, but there has been a certain amount of variation in the results reported. ${ }^{26,39} \beta$-adrenoceptor blockade reduced basal level of plasma renin activity in human subjects and experimental animals. ${ }^{17,40}$ This study showed that PRO caused a fall in the PRC, indicating that adrenergic stimulation of renin release is present under normal conditions. The administration of PRO in the sodium-depleted animals reduced the increment in PRC stimulated by LSI, suggesting that there is an interaction between sodium depletion and PRO on renin secretion in the kidney. The results also showed that there was no net secretion of renin in the hydronephrotic kidney under the circumstances either PRO alone or the combined procedure with sodium depletion. This further demonstrated that the macula densa has a critical role in the regulation of renin secretion.

To determine the effects of sodium depletion and PRO on renin synthesis, TRC and renin mRNA levels were measured in the kidney. In mice with LSI, TRC and renin mRNA levels were elevated in both the normal and hydronephrotic kidneys. When PRO was given to sodium depleted mice the levels of TRC and renin mRNA levels were reduced compared with the animals with LSI alone, indicating that $\beta$-adrenergic blockade attenuated the effect of sodium depletion on renin synthesis. The results demonstrated that there is an interaction between PRO and LSI on TRC and renin mRNA levels. On the other hand, PRC in LSI- and PRO-treated mice was lower than that with LSI alone. Furthermore, linear regression analysis showed that there was a positive correlation between levels of PRC, TRC and renin mRNA in both normal and hydronephrotic kidneys, indicating that there is an interaction between LSI and PRO on renin synthesis and secretion. As renin secretion is affected, additional post-translational interactions or an effect of $\beta$-adrenoceptor blockade at the level of the secretory pathway may occur in the kidney. Thus $\beta$-adrenoceptors have an important role in renin secretion stimulated by LSI.

In conclusion, in the hydronephrotic kidney, there was no net increase in renin secretion because of the lack of macula densa under all of the circumstances studied. The macula densa is critical for renin secretion but not for the stimulation of renin synthesis. There is an interaction between sodium depletion and $\beta$-adrenoceptor blockade on renin synthesis and secretion. These results probably reflect the combined effect of the reduced tonic stimulation by sympathetic transmitter release and of sodium depletion.

\section{CONFLICT OF INTEREST}

The authors declare no conflict of interest.

\section{ACKNOWLEDGEMENTS}

This study was funded by the Shandong Natural Science Foundation.
1 Gibbons GH, Dzau VJ, Farhi ER, Barger AC. Interaction of signals influencing renin release. Annu Rev Physiol 1984; 46: 291-308.

2 Di Sole F. Adenosine and renal tubular function. Curr Opin Nephrol Hypertens 2008; 17: 399-407.

3 Bie P. Blood volume, blood pressure and total body sodium: internal signalling and output control. Acta Physiol (Oxf) 2009; 195: 187-196.

4 Skøtt 0 , Briggs JP. Direct demonstration of macula densa-mediated renin secretion. Science 1987; 237: 1618-1620.

5 Schrier RW. Water and sodium retention in edematous disorders: role of vasopressin and aldosterone. Am J Med 2006; 119(7 Suppl 1): S47-S53.

6 Cook N, Fraser SA, Katerelos M, Katsis F, Gleich K, Mount PF, Steinberg GR, Levidiotis V, Kemp BE, Power DA. Low salt concentrations activate AMP-activated protein kinase in mouse macula densa cells. Am J Physiol Renal Physiol 2009; 296: F801-F809.

7 Molstrom S, Larsen NH, Simonsen JA, Washington R, Bie P. Normotensive sodium loading in normal man: regulation of renin secretion during $\beta$-receptor blockade. Am J Physiol Regul Integr Comp Physiol 2009; 296: R436-R445.

8 Rasmussen MS, Simonsen A, Sandgaard NCF, Hoilund-Carlsen PF, Bie P. Mechanisms of acute natriuresis in normal humans on low sodium diet. J Physiol 2003; 546: 591-603.

9 Pluznick JL, Zou DJ, Zhang X, Yan Q, Rodriguez-Gil DJ, Eisner C, Wells E, Greer CA, Wang T, Firestein S, Schnermann J, Caplan MJ. Functional expression of the olfactory signaling system in the kidney. Proc Natl Acad Sci USA 2009; 106: 2059-2064.

10 Hanner F, Chambrey R, Bourgeois S, Meer E, Mucsi I, Rosivall L, Shull GE, Lorenz JN, Eladari D, Peti-Peterdi J. Increased renal renin content in mice lacking the $\mathrm{Na}+\mathrm{H}+$ exchanger NHE2. Am J Physiol Renal Physiol 2008; 294: F937-F944.

11 Al Kattan AH, Parker JC, Noble AR. Beta-adrenoceptor mediated secretion of active and inactive renin in conscious sheep. Clin Exp Pharmacol Physiol 1990; 17: 427-437.

12 Vilas-Boas WW, Ribeiro-Oliveira Jr A, da Cunha Ribeiro R, Vieira RL, Almeida J, Nadu AP, Simoes E Silva AC, Santos RA. Effect of propranolol on the splanchnic and peripheral renin angiotensin system in cirrhotic patients. World J Gastroenterol 2008; 14: 6824-6830.

13 Dib N, Oberti F, Cales P. Current management of thecomplications of portal hypertension: variceal bleeding andascites. CMAJ 2006; 174: 1433-1443.

14 Blumenfeld JD, Sealey JE, Mann SJ, Bragat A, Marion R, Pecker MS, Sotelo J, August $\mathrm{P}$, Pickering TG, Laragh JH. Beta-adrenergic receptor blockade as a therapeutic approach for suppressing the renin-angiotensin-aldosterone system in normotensive and hypertensive subjects. Am J Hypertens 1999; 12: 451-459.

15 Kirchheim HR, Ehmke H, Fischer S, Lowe W, Persson P. Sympathetic modulation of the pressure-dependent renin release in conscious dogs. Clin Exp Hypertens A 1987; 9 (Suppl. 1): 167-180.

16 Grünberger C, Obermayer B, Klar J, Kurtz A, Schweda F. The calcium paradoxon of renin release: calcium suppresses renin exocytosis by inhibition of calcium-dependent adenylate cyclases AC5 and AC6. Circ Res 2006; 99: 1197-1206.

17 Kim SM, Theilig F, Qin Y, Cai T, Mizel D, Faulhaber-Walter R, Hirai $H$, Bachmann S, Briggs JP, Notkins AL, Schnermann J. Dense-core vesicle proteins IA-2 and IA-2\{beta\} affect renin synthesis and secretion through the \{beta\}-adrenergic pathway. Am J Physiol Renal Physiol 2009; 296: F382-F389.

18 Abdulla MH, Sattar MA, Salman IM, Abdullah NA, Ameer OZ, Khan MA, Johns EJ. Effect of acute unilateral renal denervation on renal hemodynamics in spontaneously hypertensive rats. Auton Autacoid Pharmacol 2008; 28: 87-94.

19 Carillo BA, Beutel A, Mirandola DA, Vidonho Jr AF, Furukawa LN, Casarini D, Campos RR, Dolnikoff MS, Heimann JC, Bergamaschi CT. Differential sympathetic and angiotensinergic responses in rats submitted to low-or high-salt diet. Regul Pept 2007; 140: 5-11.

20 Zhang Y, Wu J, Wang X, Morgan T. Effects of enalapril and sodium depletion on the renin-angiotensin system in hydronephrotic mice. Can J Physiol Pharmacol 2009; 87: 515-521.

21 Zhang YL, Wu JY, Wang XC, Liu L. Interaction of sodium loading and enalapril on renin mRNA and renin release in hydronephrotic mice. Acta Physiol Sin 2009; 61: 239-246.

22 Zhang DY, Morgan TO. Effects of aortic ligation on the renin angiotensin system in hydronephrotic mice. Blood Press 1999; 8: 122-127.

23 DiBona GF. Neural regulation of renal tubular sodium reabsorption and renin secretion: integrative aspects. Clin Exp Hypertens A 1987; 9(Suppl 1): 151-165.

24 Schnermann J. Juxtaglomerular cell complex in the regulation of renal salt excretion. Am J Physiol 1998; 274: R263-R279.

25 Schnermann J, Levine DZ. Paracrine factors in tubuloglomerular feedback: adenosine, ATP, and nitric oxide. Annu Rev Physiol 2003; 65: 501-529.

26 Schweda F, Friis U, Wagner C, Skott O, Kurtz A. Renin release. Physiology (Bethesda) 2007; 22: 310-319.

27 Blair ML, Gengo FM. $\beta$-Adrenergic control of renin in sodium-deprived conscious dogs: renal versus extrarenal location. Can J Physiol Pharmacol 1995; 73 : 1198-1202.

28 Zhang Y, Morgan T. Role of the macula densa in renin synthesis and secretion. Am J Hypertens 1994; 7: 448-452.

29 Bell PD, Lapointe JY, Peti-Peterdi J. Macula densa cell signaling. Annu Rev Physiol 2003; 65: 481-500.

30 Liu R, Persson AE. Simultaneous changes of cell volume and cytosolic calcium concentration in macula densa cells caused by alterations of luminal $\mathrm{NaCl}$ concentration. J Physiol 2005; 563: 895-901. 
31 Bie P, Mølstrøm S, Wamberg S. Normotensive sodium loading in conscious dogs: regulation of renin secretion during beta-receptor blockade. Am J Physiol 2009; 296: R428-R435.

32 Lorenz JN, Kotchen TA, Ott CE. Effect of $\mathrm{Na}$ and $\mathrm{Cl}$ infusion on loop function and plasma renin activity in rats. Am J Physiol 1990; 258(5 Part 2): F1328-F1335.

33 Ren YL, Garvin JL, Ito S, Carretero OA. Role of neuronal nitric oxide synthase in the macula densa. Kidney Int 2001; 60: 1676-1683.

34 Park CS, Doh PS, Carraway RE, Chung GG, Fray JC, Miller TB. Stimulation of renin secretion by ethacrynic acid is independent of $\mathrm{Na}(+)-\mathrm{K}(+)-2 \mathrm{Cl}$ - cotransport. Am J Physiol 1990; 259(4 Part 2): F539-F544.

35 Vilas-Boas WW, Ribeiro-Oliveira Jr A, da Cunha Ribeiro R, Vieira RL, Almeida J, Nadu AP, Simoes E Silva AC, Santos RA. Effect of propranolol on the splanchnic and peripheral renin angiotensin system in cirrhotic patients. World J Gastroenterol 2008; 14: 6824-6830.

36 Skoog KM, Blair ML, Sladek CD, Williams WM, Mangiapane ML. Area postrema: essential for support of arterial pressure after hemorrhage in rats. Am J Physiol 1990; 258(6 Part 2): R1472-R1478.

37 Weber MA. The role of the new beta-blockers in treating cardiovascular disease. Am J Hypertens 2005; 18(12 Part 2): 169S-176S.

38 Weir MR. Beta-blockers in the treatment of hypertension: are there clinically relevant differences? Postgrad Med 2009; 121: 90-98.

39 Hackthenthal E, Paul M, Ganten D, Taugner R. Morphology, physiology, and molecular biology of renin secretion. Physiol Rev 1990; 70: 1067-1116.

40 Keeton TK, Campbell WB. The pharmacologic alteration of renin release. Pharmacol Rev 1980; 32: 81-227. 